\title{
UM ETHOS SOBRE O BRASIL EM NOTÍCIAS DE MÍDIA NACIONAL E ESTRANGEIRA: RIO 2016 E CRISE ECONÔMICA NO RJ ${ }^{1}$
}

\author{
An ethos about Brazil in news of national and foreign media: Rio 2016 and \\ economic crisis in $R J$
}

Un ethos sobre el Brasil en noticias de medios nacional y extranjero: Río 2016 y crisis económica en el RJ

\author{
Érika de Moraes \\ Docente na Universidade Estadual Paulista, Faculdade de Arquitetura, Artes e Comunicação, \\ Campus de Bauru e PPG-EL do IBILCE-Unesp, São José do Rio Preto \\ erika.moraes@unesp.br
}

\section{Resumo}

Este artigo trata de efeitos de sentido a respeito da identidade do Brasil e do brasileiro num recorte de notícias sobre os Jogos Olímpicos Rio 2016 e a crise econômica do RJ, veiculadas em dois aplicativos de notícias, um nacional (o portal UOL) e um internacional (Le Monde). À luz do respaldo teórico-metodológico da Análise do Discurso francesa (AD), é investigado um ethos que emerge da representação da identidade nacional nessas matérias, levando em conta a relação entre a interdiscursividade, a deontologia jornalística e as tecnologias atuais. Constata-se que os efeitos do destacamento (Maingueneau) são potencializados pelas novas tecnologias de comunicação e interferem na produção de memória discursiva.

Palavras-chave: Mídia; Ethos; Brasil.

\begin{abstract}
This article deals with meaning effects regarding the identity of Brazil and the Brazilian in a news clipping about the Olympic Games Rio 2016 and the economic crisis of Rio de Janeiro, published in two news applications, one national (the UOL portal) and one international (Le Monde). With the support of the theoretical and methodological framework of French Discourse Analysis (AD), we investigate an ethos that emerges from the representation of the national identity in these news, taking into account the relationship between interdiscursivity, journalistic ethics and the current technologies. It is observed that the effects of detachment (Maingueneau) are enhanced by the new communication technologies and interfere in the production of discursive memory.
\end{abstract}

Key words: Media; Ethos; Brazil.

\footnotetext{
${ }^{1}$ Este artigo resulta de pesquisa mais abrangente desenvolvida em pós-doutoramento com bolsa Fapesp. Os resultados completos estão publicados no livro: MORAES, E de. Aplicativos de notícias, destacamento e efeitos de sentidos. 1. ed. São Paulo: Editora Unesp, 2019. v. 1. 169p.
} 


\section{Resumen}

Este artículo trata de los efectos de sentido sobre la identidad de Brasil y del brasileño, en un recorte de noticias sobre los Juegos Olímpicos Rio 2016 y la crisis económica del RJ, transmitidas en dos aplicaciones de noticias, un nacional (el portal UOL) y un internacional (Le Monde). A la luz del respaldo teórico-metodológico del Análisis del Discurso francés (AD), se investiga un ethos que emerge de la representación de la identidad nacional en esas materias, teniendo en cuenta la relación entre la interdiscursividad, la deontología periodística y las tecnologías actuales. Se constata que los efectos del destacamento (Maingueneau) son potenciados por las nuevas tecnologías de comunicación y interfieren en la producción de memoria discursiva.

Palabras clave: Medios de comunicación; Ethos; Brasil.

\section{Introdução}

A forte presença da comunicação digital na vida das pessoas faz com que o hábito de ler jornais em papel venha sendo praticamente substituído pela leitura on-line, muito especialmente por meio dos dispositivos móveis. A alta disponibilidade de notícias e os novos modos de leitura ${ }^{2}$ aumentam o potencial de impacto dos elementos destacados na produção de efeitos de sentido. É comum que se leiam apenas títulos e, se as matérias jornalísticas já são um recorte da realidade, pré-definido de acordo com uma linha editorial, aqueles são um "recorte do recorte", um aspecto particular "destacado" do assunto abordado, focado num certo posicionamento.

Levando em conta esta realidade social e a crescente influência dos aplicativos para dispositivos móveis (os chamados apps), este artigo propõe discorrer a respeito de efeitos de sentidos que impactam na cristalização de memória sobre a identidade do Brasil e do brasileiro, construídos especialmente com base nos destacamentos em títulos de notícias, mas também no diálogo que esses elementos compõem com a íntegra da narratividade jornalística. Tratamos aqui de notícias de dois aplicativos, um nacional (Portal UOL) e outro estrangeiro (Le Monde), recortando dois temas que dialogam entre si e colocam o Brasil em evidência, tanto na mídia nacional quanto estrangeira. São aplicativos que procuram resguardar o status de mídias tradicionais no atual universo diversificado da comunicação. Optamos pelo aplicativo UOL por ser um dos mais populares no Brasil e ter vínculo com o grupo Folha, responsável pelo jornal Folha de S. Paulo, de grande circulação e influência nacional. A

\footnotetext{
${ }^{2}$ A leitura tende a ser mais fragmentada e, ao mesmo tempo, mais constante, já que "as menores telas e sensores roubam do Rádio a característica de companheiro de todas as horas para informar e recolher dados em todos os momentos". (MELLO et al. 2015, p. 98)
} 
escolha do aplicativo do jornal francês Le Monde se justifica pela sua importância e credibilidade internacional.

De um recorte de corpus mais amplo (que inclui o período de dezembro de 2015 a julho de 2017), tratamos, neste artigo, de duas notícias similares (com semelhanças temáticas) sobre os Jogos Olímpicos 2016 e outras duas relacionadas à crise econômica no estado do RJ, veiculadas pelo aplicativo Le Monde e pelo UOL. O recorte teve início no jornal francês, por entender que a imprensa estrangeira noticia os fatos sobre o Brasil considerados de maior impacto internacional e, por hipótese, de um ponto de vista mais distanciado. Buscamos, então, matéria no aplicativo brasileiro que apresentasse similaridades temáticas, possibilitando perceber eventuais diferenças na abordagem. Nosso propósito é investigar a construção de um ethos em torno das identidades do Brasil e do brasileiro que emerge dessas notícias, com base especialmente nos destacamentos, entendidos como parte determinante do funcionamento da narrativa jornalística. O ethos é aqui compreendido em termos discursivos: ao materializar sentidos, as marcas verbo-visuais conferem caráter e corporalidade ao discurso construído (Maingueneau, 2001).

Não ignoramos o fato de que o rompimento de barreiras territoriais faz com que, cada vez mais, a mídia estrangeira, por sua vez, aproprie-se do olhar do país de cobertura (inclusive, por meio de trabalho realizado por jornalistas free-lancers locais em substituição a correspondentes estrangeiros), embora a delimitação deste artigo não inclua essa discussão. Ainda assim, consideramos como produtiva a expansão de olhares-leitores por meio da abrangência de fontes multivariadas de informação.

Para cumprir a reflexão proposta, este trabalho se estrutura da seguinte forma: em uma primeira seção, retoma o quadro teórico-metodológico da Análise do Discurso francesa, com ênfase na noção de destacamento e suas implicações para a comunicação midiática. Em seguida, aborda a deontologia jornalística em consonância com o quadro conceitual mobilizado. Na seguinte, apresenta o resultado das análises sobre a representação da identidade do Brasil e do brasileiro, à luz dos pressupostos contemplados. Por fim, tece algumas considerações finais.

\section{A Análise do Discurso francesa e a destacabilidade intrínseca ao funcionamento do jornalismo}

Este trabalho aciona o quadro teórico-metodológico da Análise do Discurso francesa (AD), linha desenvolvida por Pêcheux na década de 1960 e em constante processo de 
atualização, a partir do trabalho de autores contemporâneos como Maingueneau; Paveau; Krieg-Planque, Angermuller (na França); Possenti, Orlandi e diversos círculos de estudo no Brasil, país em que encontrou terreno fértil para se ressignificar. Ainda que as abordagens desses e de outros autores possam enfatizar diferentes aspectos, compartilham de um quadro conceitual comum, segundo o qual o discurso é atravessado pelo interdiscurso, imbuído de ideologia e influenciado pelo inconsciente, concepções que impactam a compreensão de sentidos na comunicação midiática. Existe um "sempre-já-dito" por trás de todo e qualquer discurso, correlato aos lugares (discursivos) em que se situam os sujeitos que se colocam como responsáveis pelos dizeres. A própria concepção de sujeito é dependente à de discurso, já que não se trata de um indivíduo no mundo nem mesmo de uma instituição (o jornal, por exemplo), mas de uma entidade fiadora de determinados posicionamentos.

Para a $\mathrm{AD}$, o discurso não tem um início e não pode ser limitado ao funcionamento interno do texto, uma vez que está ligado a suas condições de produção, à história, às relações humanas. Como diz Foucault, todo discurso repousa secretamente sobre um já dito, que não é simplesmente uma frase já pronunciada, mas um 'jamais dito'. Assim, não é preciso, nem possível, "remeter o discurso à longínqua presença da origem; é preciso tratá-lo no jogo de sua instância" (FOUCAULT, 1971, p. 21), o que significa debruçar-se sobre as condições de produção que o sustentam, as quais não são estáveis ou homogêneas.

Por esta razão, o discurso deve ser compreendido na sua relação com o interdiscurso, indispensável para a concepção proposta por Pêcheux, para quem “é impossível analisar um discurso como um texto, isto é, como uma sequência linguística fechada sobre si mesma, [...] é necessário referi-lo ao conjunto de discursos possíveis a partir de um estado definido das condições de produção" (PÊCHEUX, 1990, p. 79). É de acordo com as condições (históricas, sociais, políticas, econômicas...) específicas de um lugar e tempo, que os discursos produzem determinados efeitos e alcançam sentidos específicos.

Pensar a Análise do Discurso na contemporaneidade implica considerá-la em sua realidade pós-estruturalista, influenciada pela epistemologia anti-humanista associada à "virada linguística" para as ciências humanas e sociais, havendo a necessidade de repensar constantemente a própria teoria, sem prescindir da contribuição de teóricos visionários em seu tempo, como Jacques Lacan, Louis Althusser, Michel Foucault e Jacques Derrida (ANGERMULLER, 2016).

Compreender os discursos implica apreender os seus "contextos de enunciação", já que é no ato de enunciação que, de fato, os enunciados são constituídos. Com o conceito de 
cenografia, Maingueneau $(2005,2006)$ rompe definitivamente com a separação entre textos e contextos, compreendendo que os textos organizam seus contextos ao mesmo tempo em que os contextos são validados pelos textos. A abordagem de Maingueneau sobre a cenografia subentende a hipótese de que os signos não são saturados, ou seja, dependem de contexto para adquirir significados particulares, ao mesmo passo em que convergem para a construção contextual.

Para Maingueneau, "o que é dito e o tom com que é dito são igualmente importantes e inseparáveis" (1997, p. 46), não havendo hierarquia entre o "conteúdo" e o modo de dizer, uma vez que a eficácia de um discurso (mensurada por sua capacidade de suscitar a crença) está diretamente ligada ao ethos que ele constrói e, ao mesmo tempo, sustenta.

A enunciação, portanto, não é algo que se acrescenta à língua, mas sim serve para detectar a sua própria instabilidade interna, conforme já demonstraram estudos como os de Jacqueline Authier-Revuz (1990 [1982]), para quem a língua é confrontada à sua "não unidade" ao fazer comentários sobre si mesma - por meio das retomadas enunciativas, que são as marcas de "heterogeneidade mostrada", ou seja, uma forma de "negociação" com a heterogeneidade constitutiva do discurso em consonância com a opacidade da língua. Assumir o equívoco da língua é, também, contemplar o inconsciente como impossibilidade do controle de si e do dizer, a inatingibilidade de estancar sentidos da qual a $\mathrm{AD}$ cada vez mais se dá conta, com a contribuição da psicanálise.

Ao levar em conta o cenário atual da tecnologia dos dispositivos móveis, nossa pesquisa busca valorizar a importância dos novos suportes tecnológicos na sociedade, sem, no entanto, implicar um deslumbramento quanto à suposta sobreposição do suporte em relação a tudo aquilo que se veicula por meio dele, conforme já defendemos em trabalhos anteriores (2014, 2019). Se, por um lado, as novas tecnologias proporcionaram uma nova sociedade, pode-se considerar, de modo complementar, que a sociedade é hoje tal que permitiu o surgimento e o avanço de tais tecnologias.

Compreendemos que as noções de destacabilidade e destacamento, tais quais propostas por Maingueneau (2010, 2014), sejam de importância fundamental para o estudo de efeitos de sentido na atualidade, uma vez que esses efeitos se potencializam a partir dos "destaques" nos títulos, olhos, legendas etc. A ideia de destacabilidade implica a constatação de que os trechos salientados de um texto correspondem a um posicionamento, com forte potencial de cristalização de memória e, consequentemente, decisivo para a constituição do ethos. 


\section{A deontologia jornalística na contemporaneidade e a mídia como produtora de} identidade

Estudar o jornalismo na atualidade implica considerar que ele é afetado pela realidade pós-wikileaks, em que a deontologia se depara com o terreno movediço dos vazamentos globais de informação (CHRISTOFOLETTI e OLIVEIRA, 2011).

Christofoletti e Oliveira (2011) tratam da emergência de novas condições de operação para jornalistas e das questões ético-profissionais que o WikiLeaks traz para o jornalismo. $\mathrm{O}$ vazamento de informações por parte do WikiLeaks buscou respaldo em veículos convencionais (The Guardian, da Inglaterra; The New York Times, dos Estados Unidos; Le Monde, da França; El País, da Espanha; e a revista semanal alemã Der Spiegel), a partir dos quais se garantiu a certificação jornalística. Ou seja, houve um esforço comum entre a tecnologia hacker e a credibilidade da deontologia profissional, "a nova mídia precisou que a velha desse autenticidade ao seu produto" (CHRISTOFOLETT e OLIVEIRA, 2011, p. 92). Simultaneamente, a velha mídia se confrontou com a necessidade de enfrentar modelos alternativos de informação, colocando o jornalismo diante do dilema de lidar com novas possibilidades de acesso à informação.

Numa era em que todo usuário da rede mundial de computadores é um potencial emissor de notícias, a mediação do jornalista torna-se ainda mais essencial no sentido de contornar uma sobrecarga de informações e gerir o conteúdo noticioso. A chave dessa questão está no pressuposto de que os jornalistas estejam comprometidos com valores e princípios profissionais relacionados à visão do jornalismo como um bem público.

Bertrand (1999) aborda o conhecido conflito entre a liberdade de imprensa e a liberdade das empresas jornalísticas. A própria noção de liberdade necessita ser problematizada, já que há consenso de que uma liberdade total da mídia seria intolerável (o autor questiona: quem teria o direito de incitar o racismo ou o ódio racial?), na mesma medida em que a censura à imprensa é marca de regimes ditatoriais. Ou seja, "em todas as democracias do mundo, há um consenso: a mídia deve ser livre e não pode sê-lo totalmente" (BERTRAND, 1999, p. 22). A resposta para o aparente paradoxo estaria na deontologia, que, segundo o autor, pode assim ser definida:

No que concerne à mídia, é um conjunto de princípios e de regras, estabelecidos pela profissão, de preferência em colaboração com os usuários, a fim de responder melhor às necessidades dos diversos grupos da 
população. A excepcionalidade de que goza o jornalismo, dentre as instituições democráticas, consiste em que seu poder não repousa num contrato social, numa delegação do povo por eleição ou por nomeação com diploma ou por voto de uma lei impondo normas. Para manter seu prestígio e sua independência, a mídia precisa compenetrar-se de sua responsabilidade primordial: servir bem a população. (BERTRAND, 1999, p. 22).

Como diz o autor, a deontologia só pode ser desenvolvida se a imprensa for livre e a liberdade enfrenta obstáculos tecnológicos, políticos, econômicos entre outros relacionados a questões culturais, como o conservadorismo dos próprios profissionais de comunicação e da sociedade em que vivem, das tradições locais (por exemplo, a condição das mulheres em países mulçumanos). Isso faz com que os aspectos destacados em notícias, constitutivos de memória discursiva (retratos dessa memória e simultaneamente mantenedores dela), dependam, como não poderia deixar de ser, da rede de interdiscursividade de uma cultura dominante.

No cenário descrito, o jornalismo tido como tradicional - ou seja, vinculado às mídias convencionais, como é o caso de Le Monde e do UOL/Grupo Folha - tende, em princípio, a marcar ainda mais a sua posição em termos de comprometimento com a ética, buscando transmitir a imagem de um jornalismo sério e respeitado, cujas informações são checadas e, portanto, confiáveis, além de ter a fiança da mídia de credibilidade. O nome do veículo funciona como fiador, imagem institucional que avaliza a cena de enunciação, constituída também por seu tom respaldado no funcionamento do discurso jornalístico.

A noção de ethos é fundamental para compreender em que medida o destacamento na circulação de notícias sobre o Brasil reforça (ou, eventualmente, modifica) estereótipos sobre o país, à luz da noção da constituição de identidade(s). Analisar sentidos em torno da identidade do Brasil e do brasileiro permite esmiuçar a identificação (ou representação) do sujeito com uma posição na e pelo simbólico, já que "o lugar simbólico que os indivíduos ocupam no discurso é um lugar social. É um endereço simbolicamente definido e socialmente reconhecido que permite aos sujeitos tomar uns em relação aos outros" (ANGERMULLER, 2016, p. 29).

Coracini (2013) trata da constituição da identidade do brasileiro, com base no sentimento de identidade subjetiva, social e nacional, lembrando que falar de um povo ou de um grupo social é, por excelência, a forma de lhe dar existência. Assim, "ser brasileiro é ser o que dizem que somos e ver o outro do modo como o vemos" (CORACINI, 2013, p. 59). O que pensamos que somos e o que dizem sobre nós constituem a ilusão da unidade da 
identidade nacional. A autora analisou um corpus constituído de artigos publicados em jornais e revistas de grande circulação, o que permitiu entrever "fios de identificações responsáveis pelas representações do estrangeiro sobre o Brasil e sobre o brasileiro e pelas representações do brasileiro sobre o estrangeiro e sobre si mesmo" (CORACINI, 2013, p. 60). O sujeito é fruto de múltiplas identificações e, "apesar da ilusão que se instaura no sujeito, a identidade não é inata nem natural, mas naturalizada, através de processos inconscientes, e permanece sempre incompleta, sempre em processo, sempre em formação" (idem, p. 61).

Tendo em vista que o discurso jornalístico atua na institucionalização social de sentidos e, assim, contribui para a cristalização da memória, a autora analisa as representações sociais que se naturalizaram sobre o brasileiro. Os traços da identidade social do brasileiro que vêm à tona no discurso jornalístico permitem entrever estereótipos apresentados como efeitos de verdade, já que o imaginário em torno da imprensa a coloca num lugar autorizado a retratar o mundo.

Tais representações podem se manter ou se atualizar (parcialmente) conforme os movimentos discursivos que interferem na memória social, por isso a pertinência de estudos constantes sobre o tema. A pretensão deste artigo não é aprofundar a temática da identidade nacional, mas dialoga com ela por meio da análise do ethos que emerge num corpus em que os traços de identidade tendem a aparecer de forma mais sutil do que nos textos analisados por Coracini. Diferentemente dos artigos de opinião assinados por um articulista, o qual se coloca como sujeito fiador de uma verdade, as notícias jornalísticas, em sua representação de neutralidade, trazem à tona tais traços de identidades como se fossem respaldados por uma voz superior e incontestável. Prioriza-se aqui demonstrar como o destacamento potencializa a constituição do ethos e de memória discursiva.

\section{O Brasil e o brasileiro na cobertura dos Jogos Olímpicos Rio 2016}

Acompanhando os aplicativos Le Monde e UOL, recortamos o corpus em um período que coloca o Brasil em destaque devido à realização dos Jogos Olímpicos no Rio de Janeiro, em agosto de 2016. Focalizamos a discussão na circulação de discursos que põem em evidência o nosso país e, consequentemente, a nossa identidade, e não no funcionamento de um gênero textual específico (o do jornalismo esportivo, por exemplo). Apresentamos, a seguir, as análises de uma matéria de Le Monde e uma do UOL. 
Figura 1: Matéria Le Monde (12/08/2016)

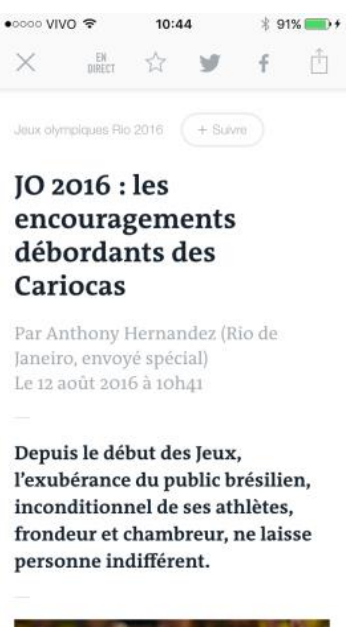

Fonte: Prnt Scrn (tela celular) gerado pelo autor

A matéria JO 2016 : les encouragements débordants des Cariocas (Jogos Olímpicos: os incentivos transbordantes dos cariocas, Le Monde, nossa tradução ${ }^{3}$ ), de 12/08/2016, assinada pelo correspondente Anthony Hernandez, enfatiza, no destacamento do título, o caráter intenso, vibrante, empolgante da torcida carioca/brasileira, por meio do adjetivo débordant. Logo no início da matéria, destaca que esse modo de torcer (transbordante, intenso) implica agressividade em relação ao adversário. O texto assim se inicia:

Il reste vingt secondes à jouer lorsque le basketteur Pau Gasol se présente, mardi 9 août, sur la ligne des lancers francs. Une véritable bronca se déchaîne dans la Carioca Arena. Des insultes fusent, accompagnées de quelques doigts d'honneur. Cette pression est-elle la cause de ses deux échecs inhabituels ? L'Espagne, qui menait de 1 point, s'incline finalement sur l'action suivante (66-65) face à la sélection auriverde.

(Trad.) Restam vinte segundos para jogar quando o jogador de basquete Pau Gasol se apresenta, na terça-feira 9 de agosto, na linha de lance livre. Um verdadeiro alvoroço se desencadeia na Arena Carioca. Insultos irrompem, acompanhados por alguns dedos de honra. Esta pressão é causa de suas duas falhas incomuns? A Espanha, que liderava por 1 ponto, se curva finalmente para a próxima ação (66-65) frente a seleção verde-amarela.

O tom narrativo da notícia contribui para a caracterização intensa da torcida brasileira. Se há uma crítica em relação ao comportamento agressivo da torcida, há também um reconhecimento (parcial admiração, talvez) de sua empolgação:

\footnotetext{
${ }^{3}$ Doravante, as traduções do francês são de nossa responsabilidade.
} 
Depuis le début des Jeux olympiques, le public brésilien, tour à tour soutien inconditionnel, exubérant et parfois excessif de ses sportifs, ne laisse en tout cas personne indifférent. Les Brésiliens eux-mêmes s'en interrogent. Le quotidien O Globo titrait ainsi dans son édition du mardi 9 août : « Les Brésiliens irritent les étrangers en vibrant dans les tribunes olympiques comme dans les stades de football.»

(Trad.) Desde o início dos Jogos Olímpicos, o público brasileiro, turno a turno em apoio incondicional, exuberante e às vezes excessivo por seus esportes, não deixa ninguém indiferente. Os próprios brasileiros se interrogam. $\mathrm{O}$ jornal $\mathrm{O}$ Globo trouxe o seguinte título na sua edição de terçafeira 9 de agosto: "Os brasileiros irritam os estrangeiros ao vibrar nas arquibancadas olímpicas como nos estádios de futebol”.

O trecho supracitado caracteriza aspectos que seriam específicos da torcida brasileira, "incondicional, exuberante e às vezes excessiva", dos quais os próprios brasileiros teriam consciência, como demonstraria a manchete do jornal $O$ Globo, citada por Le Monde, ao afirmar que o comportamento vibrante de torcida de futebol é estendido, por parte dos brasileiros, às demais modalidades olímpicas. Assim, o caráter passional da torcida brasileira é tratado em aspectos complementares: como o de um povo que dá suporte entusiasta a seus atletas e, por outro lado, desestabiliza a concentração de outros times, o que pode ser mal visto pelos estrangeiros.

O subtítulo desta mesma matéria «Ziiiiika ! Ziiiiika » contribui para uma representação pitoresca da torcida brasileira. Trata-se de um coro proferido a cada jogada da goleira norte-americana Hope Solo, numa referência jocosa a uma postagem que a atleta fizera em redes sociais, onde expressou seu medo relacionado à presença do vírus Zika no país.

Inconditionnel de ses favoris, frondeur et chambreur jusqu'à la limite, le public carioca ne manque parfois pas d'humour. En réponse à la gardienne de but des Etats-Unis Hope Solo, qui avait affiché sa peur du virus, la foule a redoublé de «Ziiiiika ! Ziiiiika ! », singeant le fameux moustique et moquant la paranoïa de l'Américaine.

(Trad.) Incondicional por seus favoritos, crítico e zombeteiro até o limite, ao público carioca, por vezes, não falta humor. Em resposta à goleira dos Estados Unidos Hope Solo, que havia apresentado seu medo do vírus, a multidão repetiu "Ziiiiika! Ziiiiika!", satirizando o famoso mosquito e ridicularizando a paranoia da americana.

Por proximidade temática, abordamos a matéria "Primeiro dia dos Jogos mostra ao mundo 'jeitinhos' brasileiros de torcer”, assinada por Gustavo Franceschini e publicada no UOL em 7/08/2016. Conforme indica o título, a notícia trata da "brasilidade" da torcida a 
partir de traços de seu chamado "jeitinho". Elenca cinco subtítulos que seriam correlatos a esses traços característicos do jeito brasileiro de torcer, expressos da seguinte forma:

1 - Brasileiros adotam azarões para torcer

2 - Cazaquistão virou "Osasco" no judô

3 - Novo grito de "Ôôô, zika!" para Hope Solo

4 - "Fura, ela!" e "Uh, vai morrer" viram gritos de incentivo

5 - Vaias incomodam tchecas no vôlei de praia

Na situação número 1, diante do favoritismo do time americano de basquete, formado por jogadores da NBA, os brasileiros optaram por dar suporte à equipe da China, homenageada com o coro: "Olê, olê, olê, olá, China! China" e "Ah, vamos virar China!". Da mesma forma, a goleira Teresa Almeida, da seleção angolana, acima do peso padrão para as jogadoras da modalidade, ganhou apoio da torcida brasileira. Na número 2, um grito de torcedores cazaques é associado pelos brasileiros ao som da palavra Osasco, fazendo com que o nome da cidade paulista fosse dito em coro, o que é compreendido como apoio ao judoca do Casaquistão. A número 3 se refere ao coro promovido com humor para a goleira americana, segundo a matéria, eleita para a "zoeira" da torcida. $\mathrm{O}$ enunciado número 4 retrata uma situação criticada pela imprensa estrangeira, em que o brasileiro recorre a gritos para intimidar os rivais, prejudicando os atletas em esportes que exigem concentração, como a esgrima. A situação número 5 , sobre vaias para o time feminino de vôlei de praia da República Tcheca, destaca o depoimento, entre aspas de uma das jogadoras estrangeiras:

\footnotetext{
"Eu jogo há dez anos e nunca vivi isso. É um tipo de patriotismo. Eu acho que não é nada pessoal contra nós, eles só não sabem o limite entre o que é apropriado para o momento e o que não é mais. E eles querem apoiar tanto a sua equipe que eles não percebem que também somos seres humanos", disse Marketa Slukova.
}

Por meio desta fala destacada, a nação brasileira é representada como patriota sem limites, caracterizada por um comportamento semelhante ao da criança que age por empolgação ao não ter discernimento a respeito de consequências de um ponto de vista mais adulto. As aspas são marcas de heterogeneidade mostrada (AUTHIER-REVUZ, 1990), indicando distanciamento, por parte da mídia, do posicionamento atribuído à atleta estrangeira, como se representasse uma visão internacional dentro de uma abordagem de viés nacional. 
Em seu conjunto, as duas matérias supracitadas destacam elementos que reforçam certos estereótipos sobre a identidade nacional: o de um povo festivo, alegre, bem-humorado, fiel (apoia incondicionalmente seus atletas), de bom coração (dá suporte tanto aos atletas brasileiros quanto àqueles considerados mais fracos), porém que ainda não atingiu um estágio de discernimento que o colocaria num patamar maduro, "Ocidental", zeloso por regras como a do respeito ao adversário e ao ser humano em geral.

\section{A crise econômica no Rio de Janeiro e sua relação com o Brasil}

Se as Olimpíadas de 2016 colocaram o Brasil em foco na mídia internacional, após a sua realização, veio à tona a crise econômica do Estado do Rio de Janeiro, com ampla cobertura pela mídia nacional, e que repercute de maneira contundente na seguinte matéria de Le Monde, publicada em 21/11/16:

Au Brésil, l'Etat de Rio ne répond plus

[Trad.] No Brasil, o Estado do Rio de Janeiro não responde mais

Figura 2: Matéria no aplicativo Le Monde (21/11/2016)

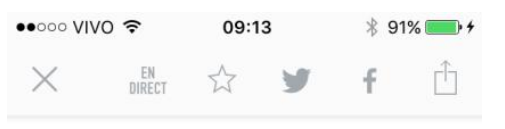

\section{Au Brésil, l'Etat de Rio ne répond plus}

\section{LE MONDE ECONOMIE \\ Le 21 novembre 2016 à 10 h27}

\section{A la crise économique et sociale s'ajoute un scandale politique.}

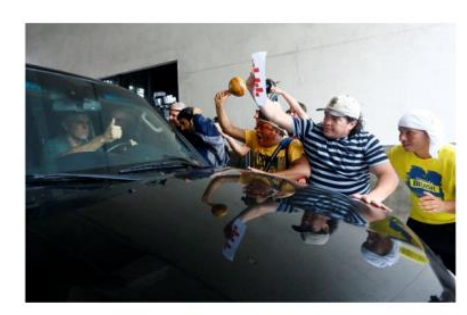

Fonte: Prnt Scrn (tela celular) gerado pelo autor

O título é bastante categórico com a expressão "não responde mais". Ainda que diversas matérias na mídia nacional tenham apontado os problemas políticos e econômicos do Rio de Janeiro, esta abordagem de Le Monde é mais enfática, com o título funcionando como 
argumento definitivo, cuja conclusão independe da leitura do restante do artigo: o Estado se desmontou, não responde mais, está falido.

Apesar do título categórico e com efeito de sentido de objetividade (uma ação acabada, objetiva), a matéria, situada na editoria de economia, inicia com texto em estilo narrativo, um recurso jornalístico que produz humanização da notícia. $\mathrm{O}$ fato é descrito não apenas como dado estatístico, mas a partir da exemplificação de um caso específico, representativo dos demais, de cidadãos que sofrem as consequências desse Estado falido.

O texto se inicia não com o Lead tradicional (resposta às questões Quem? O quê? Quando? Onde? Como? Por quê?), mas descrevendo a situação de uma cidadã, Daniela, que está há duas semanas no hospital, quando deveria ter ficado apenas uma (sua cirurgia não pôde ser realizada no dia marcado por falta do material necessário). Relata que a jovem sofre de cálculos na vesícula, conta que uma amiga visitante realizou limpeza no quarto, que estava sujo e nem mesmo tinha papel higiênico. Enfim, humaniza a personagem da notícia.

Outros elementos destacados, além do título, convergem para a compreensão da calamidade no Estado do Rio. O intertítulo subsequente é:

«Calamité publique »

[Trad.] Calamidade pública

Este item trata de questões mais estatísticas, apontando o déficit de 17,5 bilhões de reais ( $€ 4,9$ bilhões) do Estado fluminense, descrito como "à beira da falência" - expressão que serviria para relativizar, em certa medida, o fato de o Estado já estar falido (estaria prestes a falir, mas ainda não falido), mas aqui pode ser considerada basicamente como eufemística, uma vez que o título já sentenciou o Estado como falido. A matéria retoma a recessão que abalou o país desde 2015 e enfatiza: Mas em nenhum lugar - ou seja, em nenhum outro Estado do país - a situação é tão dramática como no Rio (Mais nulle part la situation n'est aussi dramatique qu'à Rio). Nesse tópico, a matéria assinala como causadores desta situação a baixa de arrecadação a partir do escândalo Petrobras, que se somou a uma "gestão dispendiosa de um governo regional atordoado pela copa do mundo de 2014 e os Jogos Olímpicos de 2016", além de uma "gestão megalomaníaca", que evocou a construção de diversos centros de saúde, quando as condições dos estabelecimentos existentes deixavam a desejar, como mostra o trecho: 
S'y ajoute la gestion jugée dispendieuse d'un gouvernement régional étourdi par la Coupe du monde de 2014 et les Jeux olympiques de l'été 2016. Une gestion « mégalomane », insiste le docteur Jorge Darze, évoquant la construction de divers centres de santé, quand l'entretien des établissements existants laisse à désirer.

[Trad.] Isso se soma à gestão julgada dispendiosa de um governo regional atordoado pela Copa do Mundo de 2014 e os Jogos Olímpicos do Verão de 2016. Uma gestão "megalomaníaca", insiste o Dr. Jorge Darze, citando a construção de vários centros de saúde, quando a manutenção dos estabelecimentos existentes deixam a desejar.

O próximo intertítulo, "Guerra Fiscal" (Guerre fiscale), remete às manifestações de diversos profissionais (policiais, bombeiros, professores, médicos), que, em suas falas destacadas, culpam a má administração e as isenções fiscais a empresas pelo não recebimento de seus salários. Alguns enunciados desses manifestantes são citados na reportagem:

« Le gouvernement a accordé des millions d'exemptions fiscales pour les entreprises et aujourd'hui on rebouche le trou qu'il a creusé ! », enrage Carlos Augusto Nogueira, un ancien employé dans le domaine de la sécurité, aujourd'hui retraité. "On paie pour l'orgie du gouvernement », appuie Sergio Luis Quintanilha, professeur de biologie, dénonçant la corruption généralisée des politiques et les soupçons de surfacturation des chantiers d'infrastructures mis en œuvre ces dernières années.

[Trad.] "O governo concedeu milhões de isenções fiscais para as empresas e hoje nós retampamos o buraco que ele cavou!", enraivece Carlos Augusto Nogueira, um ex-funcionário no campo da segurança, agora aposentado. "Nós pagamos pela orgia do governo", apoia Sergio Luis Quintanilha, professor de biologia, denunciando a corrupção generalizada de políticos e as suspeitas de superfaturamento de projetos das obras de infraestrutura implementadas nos últimos anos.

A escolha do verbo enraivecer é fundamental para a transmissão do tom com que se expressa o enunciado do entrevistado. $\mathrm{O}$ segundo verbo dicendi, apoiar, implica que a posição do segundo entrevistado se alinha à do primeiro. Os problemas do Rio de Janeiro são associados, na reportagem, a um problema mais geral do Brasil:

La ruine de Rio a mis à nu les failles du système de financement des Etats brésiliens, où règne une guerre fiscale sans merci. Chacun des 27 districts fédéraux se livrant à une surenchère de ristournes pour appâter les grands groupes et échapper à une inexorable désindustrialisation.

[Trad.] A ruína do Rio expôs falhas no sistema de financiamento dos Estados brasileiros, onde reina uma guerra fiscal sem gratidão. Cada um dos 27 distritos federais se engajam em uma competitividade de descontos para atrair grandes grupos e evitar uma desindustrialização inexorável. 
A expressão "a ruína do Rio", assim como o título, é marca material de um préconstruído que perpassa a matéria, o discurso inquestionável acerca da falta de saúde financeira do Rio, um Estado que não responde mais. A matéria faz menção à "prisão espetacular do ex-governador do Rio de Janeiro", Sérgio Cabral (PMDB), acusado de desvio de fundos, e cogita ser pouco provável que o atual governador, Luiz Fernando Pezão, não tivesse conhecimento de tais desvios, já que era o vice do acusado. No trecho, a reportagem faz as seguintes avaliações:

De fait, le scandale politique s'immisce dans la crise économique. L'arrestation spectaculaire, jeudi 16 novembre, de l'ancien gouverneur de Rio de Janeiro, Sergio Cabral (PMDB), en poste de 2007 à 2014, accusé de détournement de fonds de plus de 220 millions de reais, laisse penser que l'Etat serait, au moins en partie, victime des méfaits d'une classe politique aussi irresponsable qu'indécente.

Peu imaginent que l'actuel gouverneur, M. Pezao, qui fut l'ancien viceprésident de l'inculpé, ait pu ignorer ces agissements frauduleux. A Rio plane ainsi le sentiment que la résolution de la crise financière passera d'abord par un nettoyage politique. [grifos nossos]

[Trad.] Na verdade, o escândalo político interfere na crise econômica. A prisão espetacular, quinta-feira 16 de novembro, do ex-governador do Rio de Janeiro, Sergio Cabral (PMDB), no posto de 2007 a 2014, acusado de desvio de fundos de mais de 220 milhões de reais, sugere que o Estado possa ser, pelo menos em parte, vítima de uma classe política tanto irresponsável quanto indecente.

Pouco provável que o atual governador, Sr. Pezão, que foi o ex-vice do acusado, poderia ignorar essas atividades fraudulentas. No Rio, paira o sentimento de que a resolução da crise financeira passará primeiro por uma limpeza política.

Dados objetivos sobre valores desviados e relações entre cargos oficiais se misturam a avaliações por parte do jornal, quanto à existência de uma classe política "irresponsável" e "indecente". Ambos os adjetivos são subjetivos, porém o primeiro encontra respaldo objetivo no texto, com base nos dados estatísticos de quantias desviadas. Já o segundo é mais "valorativo" (afetivo) e depende de valores morais mobilizados, contudo, nas condições contextuais em que se encontra, vincula-se ao status de efeito objetivo do adjetivo “irresponsável”, já que ser irresponsável, entre outros aspectos, equivale a descumprir regras e a lei. São adjetivos relacionados a substantivos (irresponsabilidade e indecência) que podem ter diferentes compreensões a depender de quem os mobiliza, no entanto, da forma como o texto foi construído, simulam um efeito de objetividade e, supostamente, corroboram os elementos destacados em títulos e intertítulos: Estado que não responde mais, calamidade pública, guerra fiscal. 
Esta pode ser considerada como uma "abordagem de síntese" de toda uma cobertura sobre os problemas no Estado do Rio de Janeiro. Na ocasião, a mídia televisiva brasileira, por sua vez, mostrou continuamente imagens de manifestações de trabalhadores com salários atrasados e retratou a falta de materiais e de higiene em hospitais. Durante nossa pesquisa, o tema das dificuldades financeiras do Rio continuou repercutindo na imprensa nacional, a exemplo das seguintes manchetes da Folha de S. Paulo ${ }^{4}$ :

Sistema da Polícia Civil do Rio pode sair do ar por falta de pagamento (4.4.17)

Com operação da PF, Pezão pede ajuda a Temer para socorro financeiro (30.3.17)

Justiça do Rio impede que Pezão corte $30 \%$ dos salários de servidores da UERJ (28.3.17)

Rio promete depositar $13^{\circ}$ de parte dos aposentados ainda nesta segunda (23.3.17)

Rio deposita R\$ 920 milhões em salários de policiais e professores (14.02.17)

Crise no Rio de Janeiro sucateia rede de atendimento a mulheres (1.2.17)

Policiais civis e agentes penitenciários fazem paralisação no Rio (17.1.17)

Acordo para salvar Rio prevê redução de jornada e salário de servidores (11.1.17)

Rio de Janeiro é o primeiro Estado a negociar recuperação com governo (9.1.17)

Embora a matéria de Le Monde, acima descrita, não seja equivalente, portanto, a uma única matéria de UOL/Folha, é possível estabelecer uma relação particular, por proximidade temática e temporal, considerando a metodologia adotada neste trabalho, com a seguinte matéria publicada em UOL/Folha em 16/11/20165:

\section{Rio de Janeiro enfrenta ressaca política e econômica}

Em termos de destacamento e contextualização, a matéria apresenta semelhanças com a de Le Monde, associando a crise política à econômica. Atentando-se ao percurso de leitura com base nos elementos destacados, a reportagem apresenta os seguintes destaques, após o título:

\footnotetext{
${ }^{4}$ Disponível para consulta on-line em: http://www1.folha.uol.com.br/cotidiano/riodejaneiro/ (acesso em abril de 2017)

${ }^{5}$ Disponível para consulta on-line em: http://www1.folha.uol.com.br/poder/2016/11/1833228-rio-de-janeiroenfrenta-ressaca-politica-e-economica.shtml (acesso em abril de 2017)
} 
Linha fina - A crise no Estado envolve nomes tradicionais da política fluminense e altera o xadrez nacional

Recurso verbo-visual - com destaque para nome e perfil de políticos envolvidos na questão, a saber: Sérgio Cabral (PMDB-RJ); Eduardo Cunha (PMDB-RJ); Anthony Garotinho (PR-RJ); Luiz Fernando Pezão (PMDB-RJ); Eduardo Paes (PMDB-RJ); Moreira Franco (PMDB-RJ); Jorge Picciani (PMDB-RJ); Leonardo Picciani (PMDB-RJ); Hudson Braga; Adriana Ancelmo. Ao clicar nas setas, acessa-se o perfil de cada um dos nomes, com foto e um breve histórico sobre as acusações em torno da personalidade.

Intertítulo - Economia estremecida - acompanhado de infográfico explicando "como a despesa supera a receita líquida desde 2013, o Estado acumula déficit primário (valores em R \$ bilhões)".

Intertítulo - Euforia e Revés - contextualiza a mudança de cenário a partir do segundo mandato de Cabral, quando "a presidente Dilma Rousseff substituiu repasses diretos de verbas federais por aval para empréstimos", o que teria mantido os investimentos, mas aumentado a dívida do Estado, "fora do limite da Lei de Responsabilidade Fiscal".

Intertítulo - Lava Jato - o trecho explica que a Operação Lava Jato, deflagrada em 2014, afetou a situação financeira do Rio "ao paralisar a cadeia de negócios da Petrobras, instalada no Estado". Informa que a crise se agravava enquanto as investigações contra Cabral avançavam, culminando na sua prisão "quando a ausência de recursos no Estado atingiu seu ápice".

Nesse trecho, em particular, é citado um exemplo que poderia corroborar a “irresponsabilidade e indecência" citada por Le Monde:

\footnotetext{
Enquanto a crise se agravava, as investigações contra Cabral avançaram. O MPF mostrou que em agosto do ano passado, quando o salário dos servidores já sofria atrasos, o ex-governador comprou uma tela do artista Marcos Cardoso por R $\$ 14$ mil, com desconto de $50 \%$.

(UOL/Folha - 16/11/16)
}

Assim, pode-se notar que a crise financeira do Rio de Janeiro é associada à crise política tanto pela cobertura da imprensa brasileira quanto de Le Monde, sendo mobilizados por ambos os veículos elementos que respaldam essa associação. 


\section{Considerações finais}

O destacamento é característico do funcionamento dos veículos midiáticos, estando o jornalismo especialmente envolvido na produção de efeitos de sentido por meio de seus títulos e demais destaques. O aumento de disponibilidade de notícias ocorrido com o desenvolvimento das tecnologias digitais potencializa esses efeitos do destacamento, já que o midium, como é chamado por Maingueneau (2001, 2005), não se resume a mero suporte, mas impacta nos modos de dizer e, consequentemente, na cristalização de memória discursiva.

O cruzamento de abordagens de notícias em mídia nacional e estrangeira revela nuances nas representações do ethos sobre a identidade do Brasil e do brasileiro, por nós mesmos e pelo "outro". De ambos os olhares, interno e externo, o brasileiro é visto como povo festivo, que convive com uma classe política corrupta. Apesar da aparente divisão (o Brasil visto por si e pelo outro), uma representação afeta a outra e constitui o que se entende por identidade brasileira, já que não devemos nos esquecer da opacidade intrínseca ao funcionamento das línguas e do simbólico que subjaz os discursos - e, consequentemente, a constituição de identidades de que esses discursos são contraparte.

Se, nas matérias sobre as Olimpíadas, predomina a caracterização do jeitinho brasileiro como algo pitoresco e alegre, as matérias sobre a crise econômica do Rio de Janeiro enfatizam a corrupção generalizada e o povo é visto como vítima. Tal distinção parece compatível ao resultado de uma recente pesquisa sobre o Brasil, divulgada em Folha de S. Paulo (MENA, 2017) segundo a qual a imagem que o brasileiro tem de si é oposta a que tem do Brasil (Honestidade X Corrupção). Ao país, a corrupção, ao povo, a alegria, às vezes transformada em jeitinho. Fragmentos de memória se solidificam nos destaques midiáticos.

\section{REFERÊNCIAS}

ANGERMULLER, Johannes. Análise de discurso pós-estruturalista. As vozes do sujeito na linguagem em Lacan, Althusser, Foucault, Derrida e Sollers. Campinas: Pontes Editores, 2016.

AUTHIER-REVUZ, Jacqueline. Heterogeneidade(s) enunciativa(s). In: Caderno de Estudos Linguísticos. Campinas (SP): V.19, dez. 1990, p.25-42. Edição original: 1982.

BERTRAND, Claude-Jean. A deontologia das mídias. Bauru (SP): Edusc (Editora da Universidade do Sagrado Coração), 1999.

CHRISTOFOLETTI, Rogério; OLIVEIRA, Cândida de. Jornalismo pós-wikileaks: deontologia em tempos de vazamentos globais de informação. Universidade Federal da Bahia: Contemporânea Comunicação e Cultura. Vol.09 - n.02 - agosto de 2011. 
CORACINI, Maria José. A celebração do outro - arquivo, memória e identidade. 2. ed. Campinas: Mercado de Letras, 2013.

FOUCAULT, Michel. Sobre a arqueologia das ciências; resposta ao Círculo Epistemológico. In: Foucault e outros. Estruturalismo e teoria da linguagem. Petrópolis: Vozes, 1971, pp. 9-55. (Edição original: 1968)

MAINGUENEAU, Dominique. Frases sem Texto. São Paulo: Parábola, 2014.

. Doze conceitos em Análise do Discurso. São Paulo (SP): Editora Parábola, 2010.

. Cenas da Enunciação. Trad. Sírio Possenti e Maria Cecíla Pérez de Souza-e-Silva. Curitiba (PR): Criar Edições, 2006.

Gênese dos Discursos. Curitiba: Criar Edições, 2005.

. Análise de textos de comunicação. São Paulo: Cortez, 2001.

. Novas Tendências em Análise do Discurso. 3. ed. Campinas (SP): Pontes/ Editora da Unicamp, 1997.

MELLO, A. F.; PASE, A.F.; GOSS, B.M; SOUZA, D.R; PELLANDA, E.C.; SANTOS, F.F; SICA, $\mathrm{K}$. Jornalismo adaptado a novas telas: um estudo da linguagem jornalística nas novas interfaces móveis In: CANAVILHAS, J.; SATUFI, I. (Org.). Jornalismo para Dispositivos Móveis: Produção, Distribuição e Consumo. Covilhã: Labcom, 2015. Disponível em:

<http://www.labcomifp.ubi.pt/ficheiros/20150622-201515_jdm_jcanavilhas.pdf>.

MENA, F. Corrupção define o Brasil, mas não o brasileiro, diz estudo. Folha de São Paulo, 24 de outubro de 2017, p. A9.

MORAES, ÉRIKA DE. O jornalismo on-line sob o viés discursivo - o novo e o já dado. In: Brunelli, Anna Flora; Gobbi, Maria Cristina; Gonzales, Lucilene dos Santos; Junior, Arlindo Rebechi; Maciel, Suely; Napolitano, Carlo José; Simis, Anita. (Org.). Comunicação, Cultura e Linguagem. 1ed. São Paulo: Cultura Acadêmica, 2014, p. 41-58.

MORAES, ÉRIKA DE. Aplicativos de notícias, destacamento e efeitos de sentidos. 1. ed. São Paulo: Editora Unesp, 2019. v. 1. 169p.

PÊCHEUX, Michel. Análise automática do Discurso. In: GADET, F. \& HAK, T. (Org.) Por uma análise automática do discurso: uma introdução à obra de Michel Pêcheux. Trad. Eni P. Orlandi. Campinas (SP): Editora da Unicamp, 1990. 
Doutora em Linguística, com pós-doutoramento pela Université Paris-Sorbonne. Docente na Universidade Estadual Paulista - Unesp, Campus de Bauru, Faculdade de Arquitetura, Artes e Comunicação e no Programa de Pós-Graduação em Estudos Linguísticos do Ibilce-Unesp, Campus de São José do Rio Preto.

\section{@ $\odot \odot \odot$}

Esta obra está licenciada com uma Licença

Creative Commons Atribuição-NãoComercial-CompartilhaIgual 4.0 Internacional 